\title{
Analyses of Optimum Production Scenarios for Sustainable Power Production in Morocco
}

\author{
Soufiyan Bahetta* and Rachid Hasnaoui \\ PhD Student, Faculty of Economics and Management - Kénitra. \\ Professor-researcher, Faculty of Economics and Management - Kénitra.
}

\begin{abstract}
The Moroccan electricity system is facing several challenges, including the sustained growth in energy demand, the strong dependence on the outside, and the preservation of the environment. This article aims to demonstrate the contribution of a carbon tax and an emission cap in the development of renewable energy sources. For this purpose, we opt-in this study for bottom-up modeling, using OSeMOSYS, which is an optimization model for longterm energy planning. The results show that: taking into account both mechanisms will lead to a diversification of the production park with greater penetration of renewable energy technologies, thus reducing the overall production of fossil fuels in Morocco. Consequently, it follows that the carbon tax offers a large deployment of renewable energy sources at the expense of a transitory increase in the total cost of the electricity system.
\end{abstract}

Keywords: Electricity mix, Renewable energies, Optimization, OSeMOSYS, greenhouse gases (GHG), Morocco.

JEL Classifications: C61,P28,Q42,Q55.

\section{INTRODUCTION}

Morocco confronts serious challenges related to energy, including its strong dependence on the foreign providers, increasing demand and preservation of the environment. For this reason, the country has opted for an energy strategy anchored in the exploitation of renewable energy sources. The objective is to accomplish a $52 \%$ share of renewable energy sources in the electricity mix by 2030 . However, despite the efforts undertaken since 2009, the electricity mix is still dominated by fossil energy sources for which the country can only suffer the consequences of international price fluctuations.

Morocco's electricity generation system has depended on hydroelectricity for many years. This heavy dependence on hydropower means that the generation system is affected by seasonal cycles. Annual periods of prolonged dry seasons (1983 - 1985 and 1992 - 1993), linked to low rainfall during the rainy seasons, have resulted in an energy reduction. Thermal power generation was introduced to supplement hydroelectric power after the drought, which signaled the need to diversify the country's generation system. The introduction of thermal power generation took place in 2001 with the construction of a coal-fired power plant with an installed capacity of $1360 \mathrm{MW}$ in Jorf lasfar. The Jorf lasfar thermal power plant (JLEC) was then expanded to $2056 \mathrm{MW}$ with the addition of $2 \times 350 \mathrm{MW}$ in 2014 . This marked a gradual transition to thermal generation in the country. In 2015, the installed capacity was $8159 \mathrm{MW}$, of which $1770 \mathrm{MW}$ (21.7\%) came from hydro dams and pumped storage, 5431

*Address correspondence to this author at Laboratory of Economics and Management of Organizations, Faculty of Economics and Management, Ibn Tofail University - Kénitra; E-mail: soufianebahetta@ gmail.com
MW (66.5\%) from thermal power plants, 797 MW (9.8\%) from wind farms, and only $161 \mathrm{MW}(2 \%)$ from solar systems (ONEE,2015).

The development of the electricity production park shows that Morocco is slowly turning towards the use of renewable energy sources. However, environmental repercussions and the fluctuating prices of fossil fuels on the world market have made it necessary to implement sustainable energy production technologies. Renewable energy sources renew themselves naturally at rates that far exceed their consumption. Morocco is endowed with various renewable energy resources, which can be used to meet its energy needs. Solar radiation is perfect throughout the year, with average radiation of approximately $5.3 \mathrm{kWh} / \mathrm{m} 2$. The country also benefits from a significant wind resource in several regions with an average wind speed of $9 \mathrm{~m} / \mathrm{s}$ (Zouiri and El messaoudi, 2018).

The main problem in the implementation of renewable energy systems, especially in developing countries like Morocco, is their high initial investments. However, the progress of scientific knowledge should lead in the future too much better-improved technology, at a reasonable and affordable cost. Moreover, the failure to take into account greenhouse gas (GHG) emissions generated by electricity production leads to a negative externality from an economic point of view, ignoring the external cost of carbon emissions. A carbon tax or an emission cap could be effective instruments to decarbonize the electricity system. Also, both instruments provide an incentive for technological change (Afif, 2012).

Energy modeling frameworks provide different tools for the analysis and planning of future investments. The aim is to determine the energy mix that will enable the planned objectives to be achieved and the needs of the sector to be met, 
while respecting technical and environmental constraints, to explore possible development paths towards energy independence. The applications of energy foresight are rich because they have become an abundant practice in developed countries.

To our knowledge, this study first to assess the impact of taking into account the constraints of $\mathrm{CO}_{2}$ emissions on the Moroccan electricity mix. We used the OSeMOSYS tool to determine the current production growth plan in Morocco and to analyze alternative scenarios, highlighting the impact of different production systems on emissions. This study aims to show the contribution of the two instruments related to the carbon tax and the emission cap to the development of renewable energy sources in the electricity mix.

To understand our problem, our research will be articulated around four points. The first is devoted to the study of the literature review relating to the empirical studies concerning the evaluation of the optimal strategies of the electric systems. In the second point, we will present the characteristics of the Moroccan electrical system. The third section will see the empirical methodology adopted and the description of the proposed scenarios. Finally, the main results of the empirical study on the evaluation of the impact of the two constraints in terms of greenhouse gas emissions on the Moroccan electricity mix will be analyzed.

\section{LITERATURE REVIEW AND HYPOTHESIS DE- VELOPMENT}

Several studies have tried to evaluate the optimal investment strategies for electricity production (Becerra-Lopez and Golding (2008); Mondal and al. (2010); Mondal and al. (2011); Lienert and Lochner (2012); Aliyu and al., (2013); Brand and Missaoui (2014); Chaudry and al. (2014); Wu and Huang (2014); Shahmohammadi and al. (2015)), but the future development of the power park in Morocco has not been analyzed in different scenarios for reducing greenhouse gas emissions.

Bazmi and Zahedi (2011), described the difficulty of developing an efficient energy policy, which must take into account the different technical characteristics related to power generation technologies and other economic variables. As a solution, the authors recommend the use of mathematical models of energy planning optimization (MOMPE) to evaluate energy sector policies.

Previous work related to the impact of taking into account a GHG emission constraint on the power system includes (Nakata and al. (2001); Yang and al. (2015); Capros and al. (2012)). Studies by Nakata and al. (2001), used a partial equilibrium model to assess the impact of the carbon tax on the Japanese electricity system during the period 1995-2040. These researchers concluded that the tax was an effective instrument, but did not provide more details on the choice of system for production technologies that achieve emission reduction.

Yang and al. (2015), used the CA-TIMES model (The Integrated MARKAL-EFOM System), to analyze how the Californian energy system could reduce $80 \%$ of greenhouse gases during the period 2020-2050. The results show that the electrification of the industry and transport sectors from wind power, solar power after 2030 or by carbon capture, storage (CCS), and nuclear is necessary to achieve the emission target.

Capros and al. (2012), applied the emission cap using a hybrid partial equilibrium model to analyze the decarbonization of multisectoral energy systems in the European Union during the period 1990-2050. The results show that the use of renewable energy and low carbon energy (nuclear and CCS) will contribute to a significant reduction in emissions, but the relative timing of the transitions that appear in the system is not explicitly demonstrated.

More recently, an Open-Source Energy Modeling System (OSeMOSYS) has been developed by the renowned KTH Royal Institute of Technology in Stockholm. OSeMOSYS represents a flexible and comprehensive Linear Mixed Integer Programming (MILP) framework for planning long-term energy strategies (Bazilian and al. 2012).

The MILP is a method used to assess medium and long-term impacts in power grids of economies of different sizes and development cycles (Howells and al. (2011); Welsch and al. (2012); Welsch and al. (2014)). Under its basic structure, OSeMOSYS forms a testing framework for developing different energy models, particularly in developing countries. More advanced forms include additional blocks for determining demand types, demand trends, and storage options (Welsch and al., 2012). Lately, Groissböck and Pickl (2016) have carried out improvements to the OSeMOSYS model, including multi-objective functions (adjustable weights on costs and emissions).

OSeMOSYS has been used by other researchers to model the long-term electricity mix in Tunisia (Dhakouani and al. 2017). This study aims to assess global energy security issues. The authors concluded a reduction in energy dependence and emissions with minor increases in the costs of the Tunisian power system.

Awopone and Zobaa (2017), introduced carbon minimization policies on Ghana's electricity mix during the period 2010 2040. The optimization results show diversification of the production mix with greater penetration of renewable energy technologies, thus reducing the overall production of fossil fuels in Ghana.

Lyseng and al. (2016), assumed several carbon price scenarios in the city of Alberta during the period 2010-2060. The results show that a transition to high-cost technologies is needed to reduce the volume of emissions, thereby increasing the expected cost of the power system.

The study will contribute to enriching the literature mentioned above, using the OSeMOSYS model to assess the impact of taking into account a greenhouse gas emission constraint on the Moroccan electricity mix. In this sense, our research hypothesis is as follows:

H1: The application of a carbon tax in the Moroccan electricity system will lead to massive use of renewable energy sources in the electricity production mix, while a $\mathrm{CO}_{2}$ emission cap will lead to reduced use of renewable energy sources. 


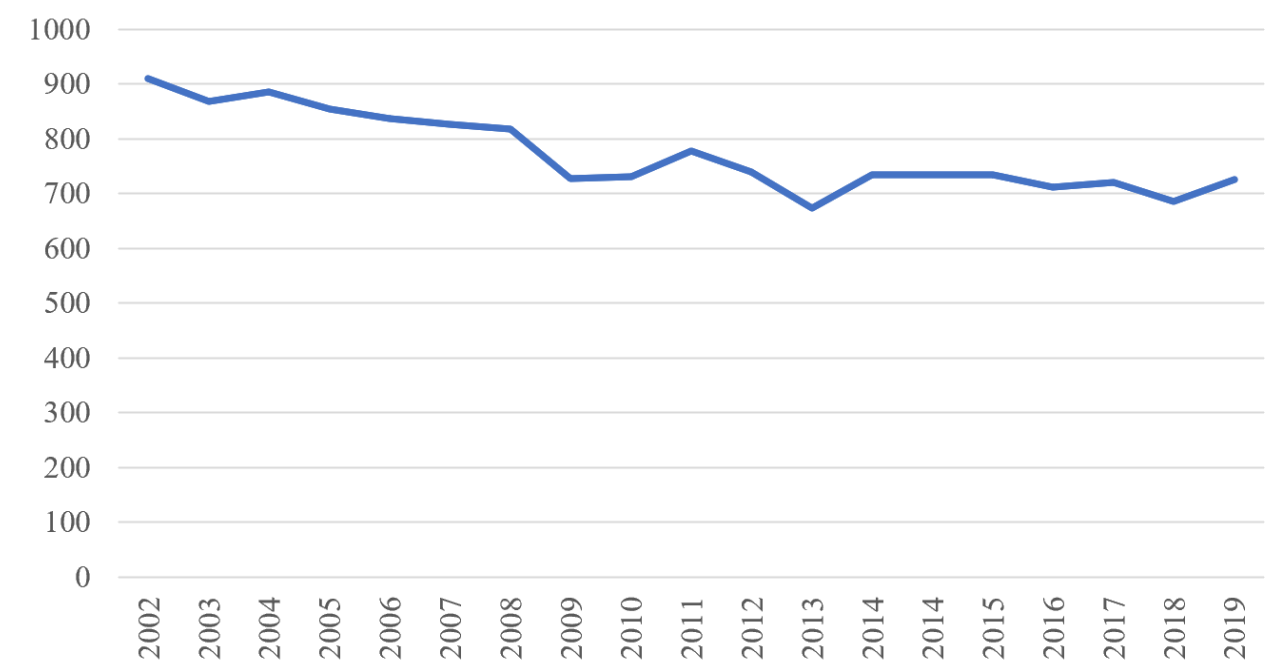

Fig. (1). Evolution of gross electricity demand during the period 2002 and 2019.

Source: Realization of the authors - ONEE data.

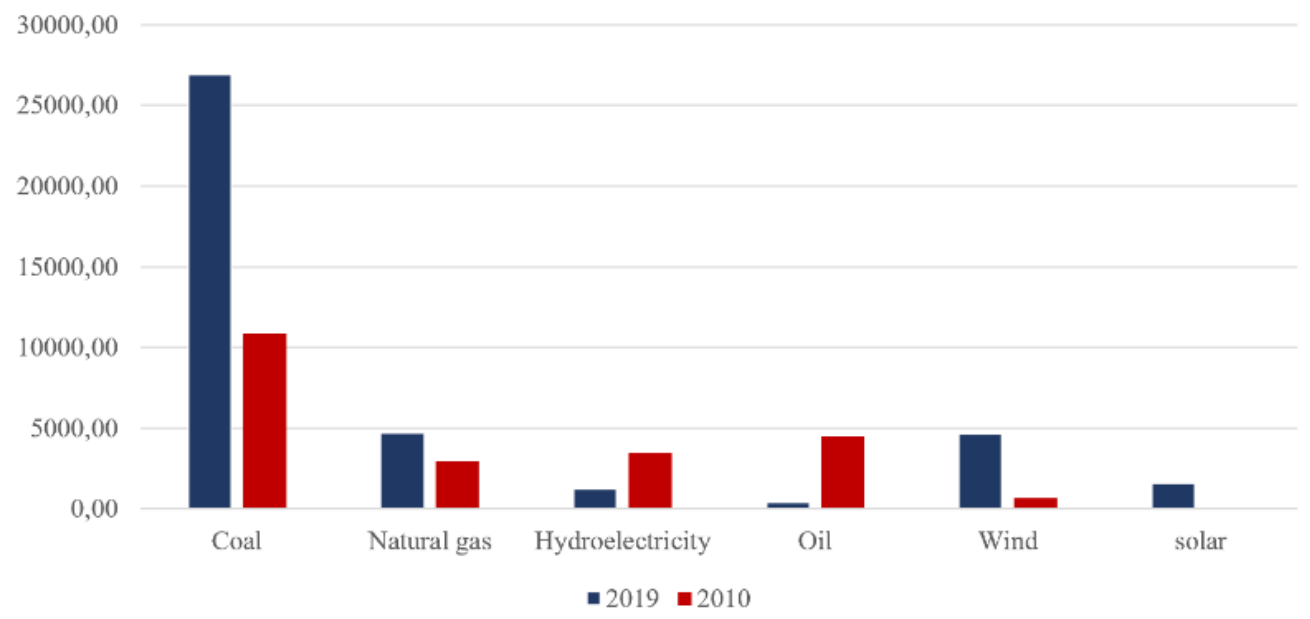

Fig. (2). Evolution of the electricity generation mix between 2010 and 2019.

Source: Realization of the authors - ONEE data.

\section{THE SITUATION OF THE MOROCCAN ELEC- TRICITY MARKET}

This section describes the characteristics of the electricity supply and demand situation in Morocco, as well as the current structure of the Moroccan electricity market.

\subsection{Demand}

The gross electricity demand reached 38,852 GWh in 2019. The latter evolved significantly during the 2004-2019 period, with an average annual growth of around $5.3 \%$ (Fig. 1). The reason for this growth can be explained mainly by population growth, the rapid development of industrialization, and the improvement of living standards, which have allowed the import of a large amount of electricity. To this end, the country's electricity demand is expected to quadruple by 2030 (reaching 95 TWh) (Chentouf and Allouch, 2018).

This continuous progression is the result of the increase in the electrification rate of Moroccan rural areas under the PERG program (global rural electrification program) launched in 1995. This national program (overall investment budget of 22.4 billion dirhams) has increased the electrification rate from $18 \%$ to $99.72 \%$ in 24 years and has connected about 45392 villages to the national grid, and installed domestic photovoltaic (PV) systems in more than 70000 households (MEME, 2019).

\subsection{Supply}

The power generation mix is mainly characterized by conventional technologies. Morocco is interconnected with the neighboring countries, Algeria and Spain, by electricity exchange agreements which enable the countries to exchange power ressources. The overall exchange capacity of Morocco and the neighboring countries is $3800 \mathrm{MW}$, of which 2400 MW is connected with Spain and $1400 \mathrm{MW}$ with Algeria. Fig. (2) presents the technological shares in the production mix during the years 2010-2019.

Referring to fig. (2), the electricity production in Morocco injected around $38890 \mathrm{GWh}$ towards the end of 2019. This is an amount of energy that was only about $22640 \mathrm{GWh}$ nine 


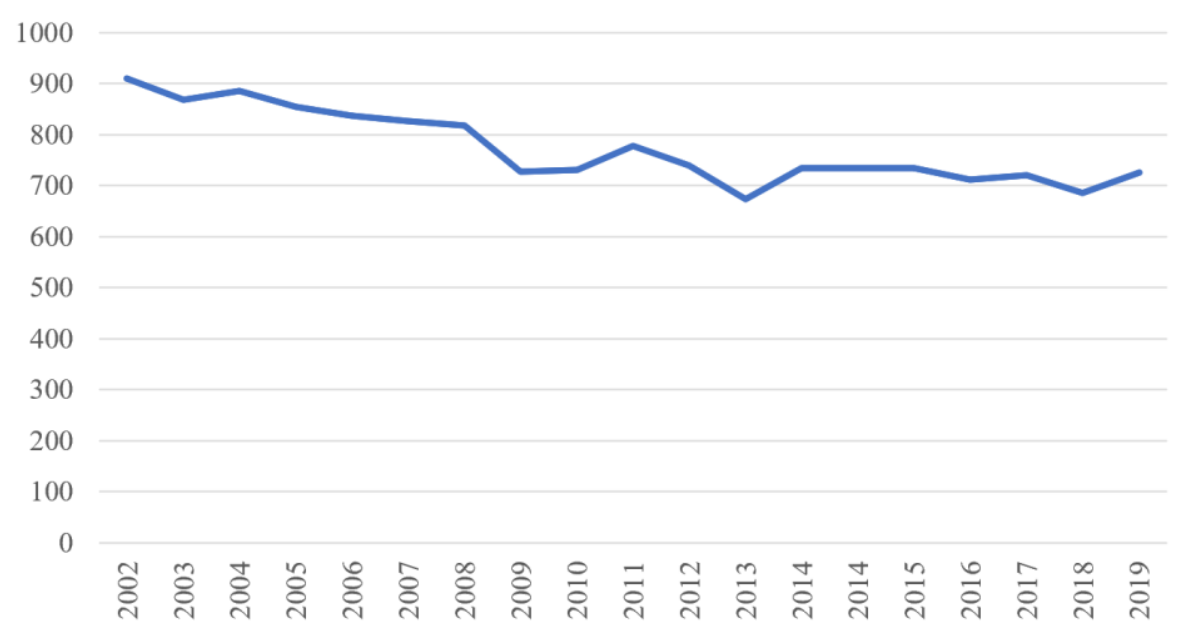

Fig. (3). $\mathrm{CO}_{2}$ emissions by electricity generation, 2002-2019 $\left(\mathrm{gCO}_{2} / \mathrm{kWh}\right)$ Source: Realization of the authors - ONEE data

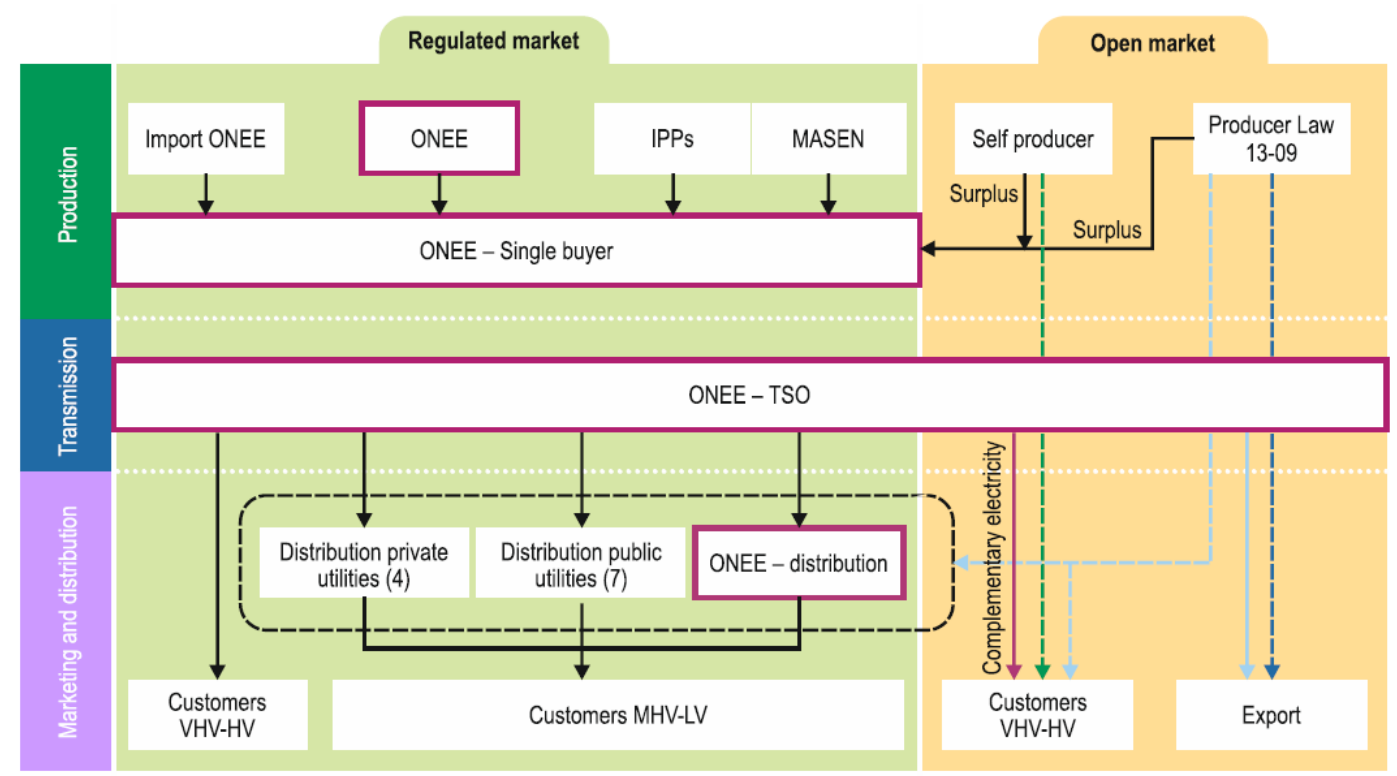

Fig. (4). Structure of the national electricity market.

Source: (IEA Report, 2019).

years ago. This amount of energy is strongly dominated by carbon-intensive sources $(82.3 \%)$. Moreover, in the product injected into the national grids for 2019, coal holds the largest share with $69.16 \%$, followed by natural gas $(12.07 \%)$ and a small share of oil, which fell to $1.1 \%$ compared with $19.96 \%$ in 2010 . Renewable energy sources have also seen a certain evolution in the production mix during the period 2010- 2019. This evolution mainly concerns wind and solar energy with a total share of $15.9 \%$. Hydropower has a low share of $4.25 \%$, which can be explained by water stress caused by the silting up of dams. This structural change is one of the objectives of the national strategy.

Electricity generation is the sector that emits the most $\mathrm{CO}_{2}$. During the period 2002-2019, emissions rose from $910.4 \mathrm{~g}$ $\mathrm{CO}_{2} / \mathrm{kWh}$ to $725 \mathrm{~g} \mathrm{CO}_{2} / \mathrm{kWh}$ in 2019 , except for the years 2011 and 2014, which marked a significant increase (Fig. 3). The reason for this decrease can be explained by the contribution of renewable energy sources; solar and wind, in the production system. Also, the emissions generated from fossil fuels in Morocco in 2019 is estimated to surpass 68.9 thousand tonnes of $\mathrm{CO} 2$, of which $52 \%$ is generated from oil products, $45 \%$ from coal, and $3 \%$ from natural gas.

\subsection{Structure of the Moroccan Electricity Market}

Like other emerging countries, Morocco has been improving electricity sector reforms for several decades. In 1994, before the PERG program began, the generation was liberalized to independent power producers. This was the first step in the reform of the Moroccan electricity sector and the end of the ONEE monopoly (Benhima, 1999).

In 2008, the self-production scheme was created, allowing private production of electricity for self-consumption. The aim was to make the electricity supply reliable. This led to a reduction in the ONEE electricity production from $82.7 \%$ in 2000 to $59 \%$ in 2012 . This system is generally used by large industrial companies. 
To improve the security of the electricity supply, Morocco has undertaken several measures to encourage the integration of renewable energies in the Moroccan electricity system:

- The creation of a renewable energy market.

- Access to high, medium, and low voltage networks for all producers of renewable energy.

- The possibility for renewable energy producers to create transmission lines for their use when the capacity of the national electricity grid and interconnections is insufficient.

The Moroccan electricity market has a hybrid structure in which a regulated market, ensured by the single purchaser (ONEE) and by the distribution companies, exists in parallel with a competitive retail market ensured by the renewable energy producers and the self-producers. As illustrated in Fig. (4), the regulated market includes Masen (Moroccan Agency for Sustainable Energy) as a central player in renewable energies, which is raising the public supply of electricity, mainly through solar and wind power. At the same time, it supervises with the ONEE the international calls for tenders of renewable energy producers. The ONEE remains a vertically integrated player, it is authorized to buy electricity wholesale and sell it to distribution companies. Through its monopoly in the management of the transmission network, it is also responsible for dispatching, planning, and maintenance of the electricity system.

With the creation of the renewable energy market, the electricity mix will benefit more from the integration of renewable energies, mainly solar and wind power. In this market, consumers have the possibility of negotiating supply agreements with producers on a bilateral basis. This is done through the guarantee of the distribution companies, which are obliged to supply complementary energy to the consumers of renewable energy to ensure their demand. To achieve the objectives set out in the national energy strategy, Morocco has put in place three green energy marketing models:

- The centralized supply model: is based on a public auction program, for which ONEE awards power purchase agreements with renewable energy producers.

- The self-generation model: allows energy-intensive industries to generate their output up to $50 \mathrm{MW}$ of installed capacity. Excess energy must be sold to ONEE under commercial terms agreed bilaterally between the self-generator and ONEE.

- The direct retail model allows generators to sell their energy directly to end consumers connected to the national grid (all voltage levels) under an electricity supply contract. At the same time, surplus energy must be delivered to the ONEE or distribution companies, up to a limit of $20 \%$ of their annual production.

In this context, the liberalization of the electricity market for renewable energies is a strategic step for the country's economic development. On the one hand, it stimulates the attractiveness of investments and, on the other hand, it guarantees a cheaper and reliable supply. However, the conventional market is still subject to a long-term contract (20 to 30 years power purchase agreement), which prevents the transition to full liberalization. In the years to come, Morocco is likely to liberalize the market if the liberalization of the renewable energy market has borne fruit, demonstrating the scope for a mixed regime before reaching a completely free market (Choukri and al. 2017).

\section{METHODOLOGY AND DATABASE}

\subsection{OSeMOSYS Energy Model}

The study of greenhouse gas (GHG) emissions reduction of the Moroccan electricity mix proposed in this paper, uses a bottom-up optimization modeling framework. This modeling approach allows to study in detail the implications of energy strategies on the development and deployment of technologies on the one hand, and on the other hand, indicating to decision-makers the optimal cost paths to reach the given objectives.

OSeMOSYS is an explicit and technological energy system optimization offer model well suited for analysis and planning. Thus, we have applied this modeling tool to determine the optimal investment strategy and power plant shipment for Morocco from 2015 to 2050. Although it is less complex than other models, OSeMOSYS results have been validated with MARKAL and a TIMES-PLEXOS coupling, making it suitable for many applications.

The objective function of the OSeMOSYS model is to determine the optimal production system to meet the demand while minimizing the total discounted cost:

$$
\begin{aligned}
& \text { Minimise } \sum_{y} \sum_{t} \sum_{r} T C_{y, t, r}=O C_{y, t, r}+C C_{y, t, r} \\
& +E P_{y, t, r}-S V_{y, t, r}, \forall_{y, t, r}
\end{aligned}
$$

Where $T C_{y, t, r}, O C_{y, t, r}, C C_{y, t, r}, E P_{y, t, r}, S V_{y, t, r}$ represents the total discounted cost, operating cost, investment cost, technology emission penalty, and salvage value, respectively. $\mathrm{y}, \mathrm{t}, \mathrm{r}$, are the year, technology, and region indices, respectively. A full description of the OSeMOSYS methodology is presented in the work of (Howells et al. 2011).

The database adopted in this study used the configuration of the TEMBA model as a reference. The data input to the model was collected from several sources. The technology costs were taken from the European Commission's report on the assessment of energy technology benchmarks. The choice of this report is justified by the fact that most of the energy investment partners in Morocco are members of this commission. While the installed capacities and contributions to Morocco's electricity supply were taken from the annual reports published by the ONEE. The data related to the $\mathrm{CO}_{2}$ emissions generated by the Moroccan electricity fleet were taken from the IEA database.

The reference electricity system (RES) is a basic representation of the actual electricity system in the country. It is used to describe the electricity supply structure. Primary energy resources are considered inputs for technologies. The Moroccan model is characterized by nine technologies including coal-fired power plant, oil-fired power plant, natural gas 
Table 1. Main Input Data.

\begin{tabular}{lccccccccc}
\hline & Units & \multicolumn{7}{c}{ Electricity generation sources } \\
\hline & & Coal & Oil products & $\begin{array}{c}\text { natural } \\
\text { gas }\end{array}$ & Hydro & CSP & PV & Wind & PSP \\
\cline { 3 - 10 } Capital cost & & & & & & & & \\
Fixed costs & $\mathrm{USD} / \mathrm{kW}$ & 1600 & 550 & 850 & 2200 & 5260.8 & 924.79 & 1386 & 3000 \\
Variable costs & $\mathrm{USD} / \mathrm{kW}$ & 26.7 & 16.5 & 21.25 & 66 & 72.84 & 16.66 & 37.8 & 45 \\
Efficience & $\mathrm{USD} / \mathrm{GW}$ & 1.25 & 3.05 & 0.55 & 0.83 & 0 & 0 & 0 & 0 \\
Availability factor & $\%$ & 45 & 40 & 58 & - & - & - & - & - \\
Max capacity factor & $\%$ & 90 & 95 & 90 & 95 & 100 & 100 & 100 & 100 \\
Life cycle & $\%$ & 90 & 95 & 90 & 42 & 42 & 17 & 40 & - \\
Residual capacity & Years & 40 & 30 & 30 & 60 & 32 & 25 & 20 & 60 \\
Cost of fossil fuel imports & M-USD/PJ & 2545 & 1830 & 834 & 1306 & 2 & 20 & 796.5 & 465 \\
\hline
\end{tabular}

*All data is relative to 2015 e some parameters are evolving during the time horizon.

Source: European Commission 1and ONEE

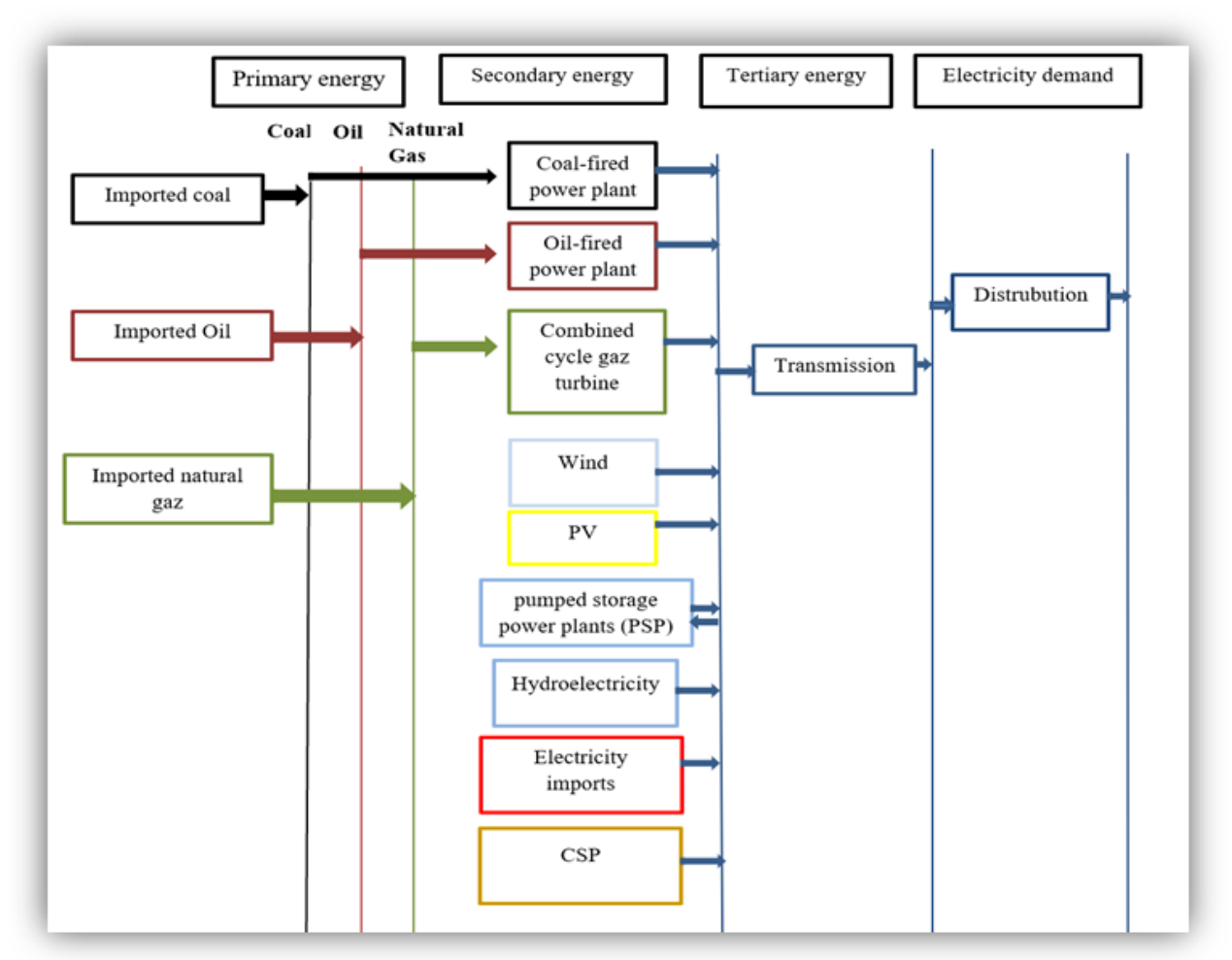

Fig. (5). Scheme of the Morocco electricity system.

Source: Realization of the authors.

combined cycle power plant, wind farm, solar photovoltaic power plant, concentrated solar power plant, hydropower, pumped storage power station (PSP), and imports. The level of transmission and distribution indicates the technical characteristics for the connection of the electricity production with the final consumers. In general, transmission networks introduce high-voltage electricity and give it to the distribution infrastructure. Finally, the level of demand represents the electricity that arises from transmission and distribution to meet final demand. Figure 4 illustrates the model of Morocco used in this study, demonstrating energy technologies and vectors.

\subsection{Description of Scenarios and Assumptions}

The proposed scenarios are based on cost minimization. They are divided into three main themes: the baseline scenario, the carbon tax scenario, and the $\mathrm{CO}_{2}$ emissions cap scenario. These policy interventions are all variants of the baseline scenario, subject to different constraints in each scenario. These scenarios present possible future tracks to promote renewable energy production in Morocco.

\footnotetext{
${ }^{1}$ Energy Technology Reference Indicator Projections for 2010-2050," European Commission, Joint Research Centre, Institute for Energy and Transport, Luxembourg: Publications Office of the European Union, 2014.
} 


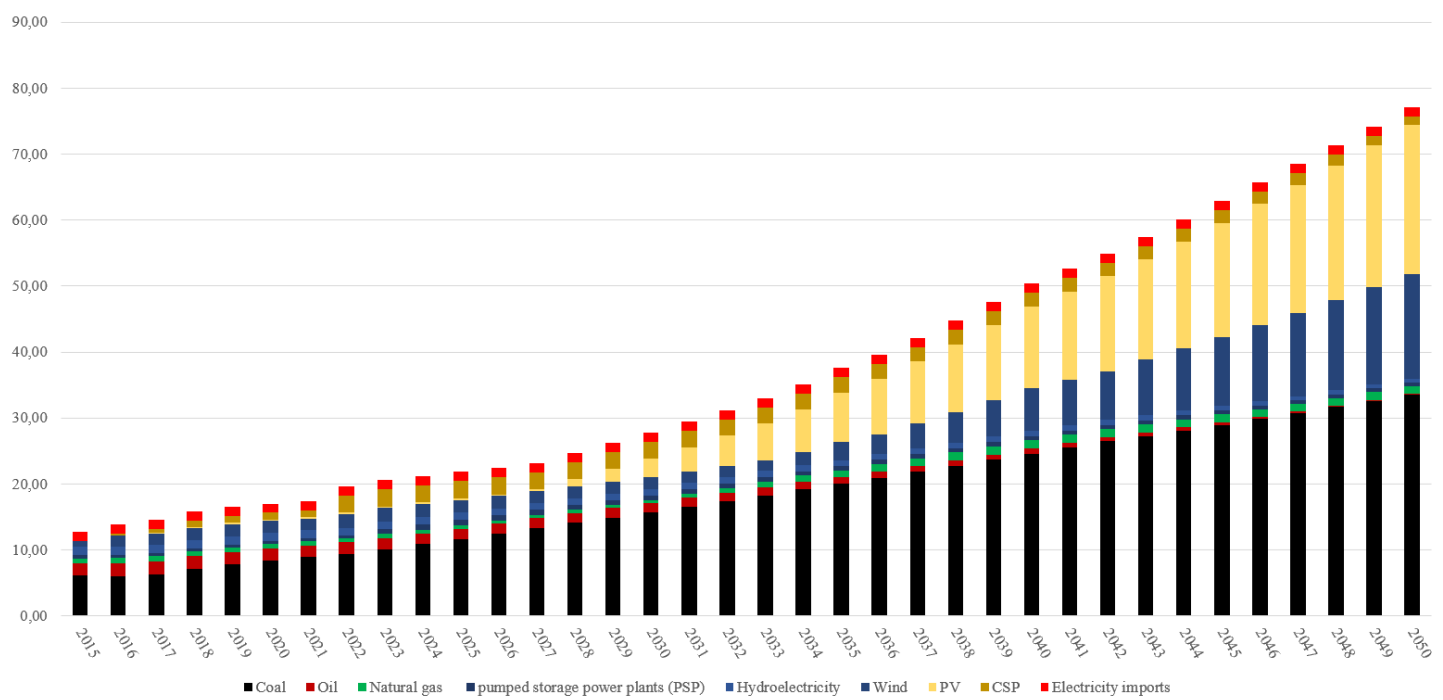

Fig. (6). Evolution of the Moroccan electricity mix in the baseline scenario during the modeling period 2015-2050 in (GW).

Source: Realization of the authors.

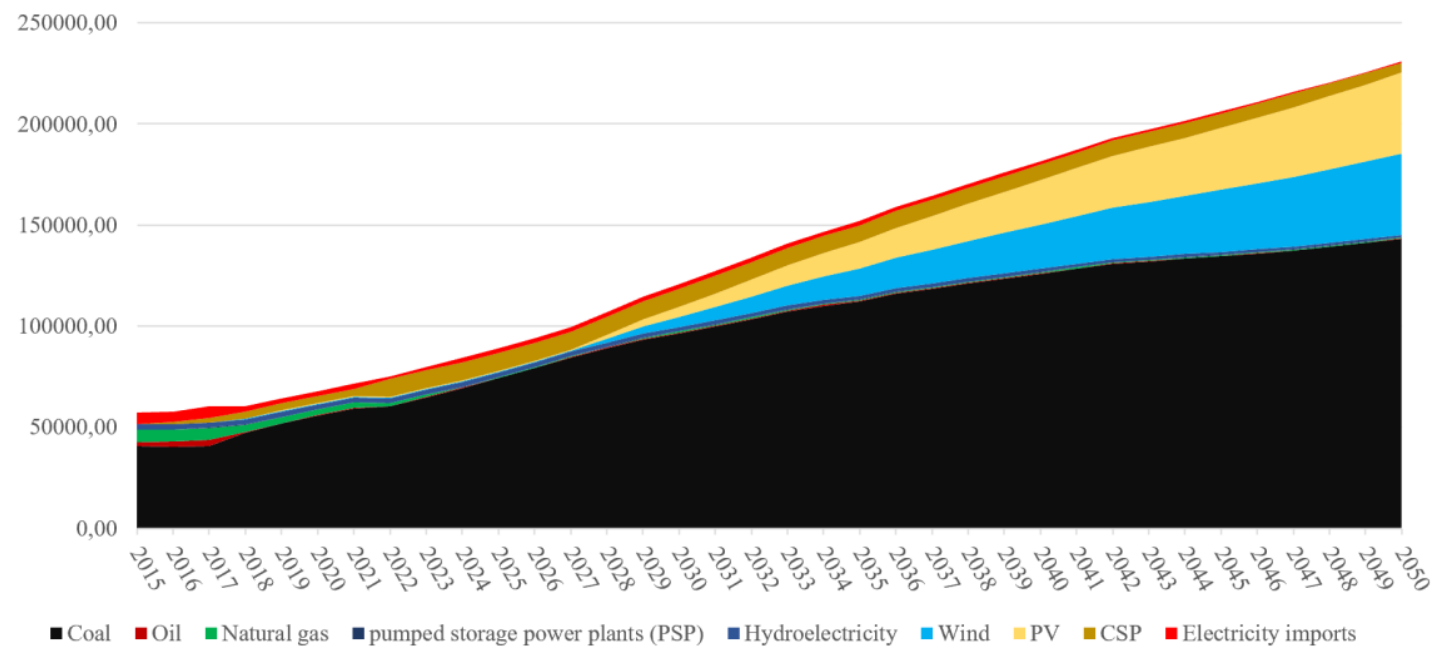

Fig. (7). Evolution of the Moroccan electricity generation mix in the baseline scenario during the modeling period 2015-2050 in (GWH). Source: Realization of the authors.

- The reference scenario (or BAU): is the least expensive power generation system, which continues the trend of existing energy policies. To get closer to the observed production, the model has been calibrated for the period 2015-2017. This calibration was carried out in two steps, the first one refers to the limitation of installed capacities and the second one concerns the constraint on production. This scenario assumes no policy intervention and serves as a reference for the analysis of other scenarios.

- The $\mathrm{CO}_{2}$ emission cap scenario is the low-cost electricity generation system under the maximum $\mathrm{CO}_{2}$ emission constraint. This scenario attempts to analyze the impact of the electricity system in the face of a $25 \%$ emissions reduction target

- The carbon tax scenario: is the least expensive electricity generation system under a carbon tax. This scenario assumes a carbon tax of $\$ 50 /$ tonne of $\mathrm{CO}_{2}$ introduced in 2020 that will increase to $\$ 125 /$ tonne of $\mathrm{CO}_{2}$ in 2050 . The taxes are applied to polluting coal, oil, and natural gas power plants

In all of the proposed scenarios, we have made some fundamental assumptions to define the structure and overall context of the modeling effort. The following parameters are held constant throughout the analysis:

- The discount rate is assumed to be $5 \%$.

- The currency unit is the USD.

- Electricity imports are assumed to be a fictitious technology with a total capacity set at $1400 \mathrm{MW}$ throughout the modeling period.

- Losses in transmission and distribution systems are taken into account.

- Electricity demand follows the historical trend in Morocco and is appropriate to official projections. 


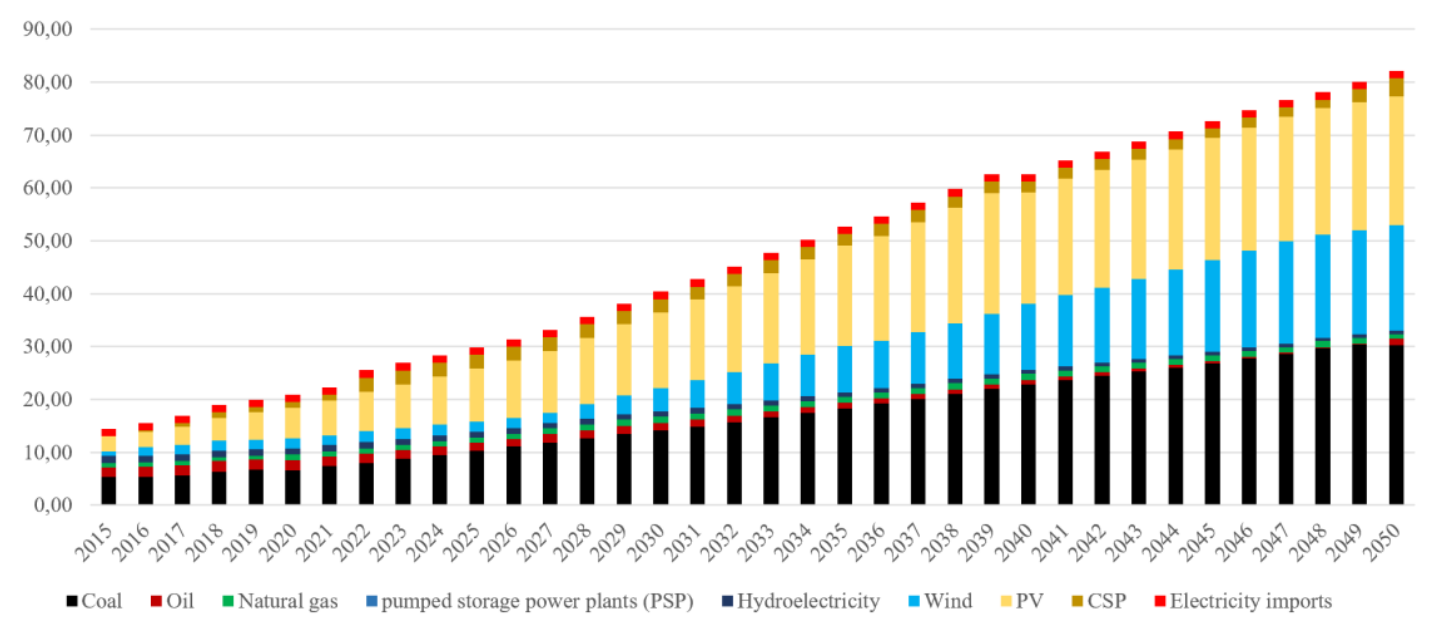

Fig. (8). Evolution of the Moroccan electricity mix in the $\mathrm{CO}_{2}$ emissions cap scenario during the modeling period 2015-2050 in (GW) Source: Realization of the authors.

- The model only takes into account carbon dioxide $\mathrm{CO}_{2}$ emissions, as these are the most common greenhouse gas emissions.

\section{RESULTS AND DISCUSSION}

\subsection{Technical Results}

The technical results from the optimization model give the least costly power generation mix and the installed capacity of each technology over the entire model period in the given scenarios.

\subsubsection{Reference Scenario}

As illustrated in Fig. (6), the OSeMOSYS model predicts a significant share of coal and integration of renewable energies (mainly photovoltaic and wind), in the electricity mix during the whole period of the model, due to the decrease of capital costs in the time horizon, which makes them more and more competitive. In the years 2036-2050, the decommissioning of oil-fired power plants is compensated by natural gas, CSP, and hydropower, which has become profitable in terms of investment. When the model had fully utilized the installed capacity of PV and wind power, PSP was not considered as a cheaper alternative for electricity generation, due to higher investment costs.

Renewable energies will contribute $7.4 \%$ to meeting electricity demand in 2015. A share that has become $27.9 \%$ in 2040 with the growing investments in wind power and solar energy. Coal-fired power remains an important source of electricity generation throughout the planning period, constituting a basic technology. Petroleum-based power plants cease production at a time when renewables hold $35.1 \%$ of the production mix in 2046.

The natural gas-fired combined-cycle power plant produces small amounts of electricity. This is due to the need for primary energy, which constitutes high prices. Imports become an important source for production, they continue to supply electricity until 2050. It should be noted that the integration of renewables into the optimal production system was based on their economic costs.

\subsection{2. $\mathrm{CO}_{2}$ Emissions Cap Scenario}

The $\mathrm{CO}_{2}$ emissions reduction target affects the deployment of clean technologies. Fig. (8) shows the evolution of the installed capacity of technologies under a single $\mathrm{CO}_{2}$ emissions constraint. The introduction of this target has led to significant deployment of renewable energy. Compared to the baseline scenario, the model projects an additional renewable energy capacity of $8.2 \mathrm{GW}$ by 2050 . The restriction of $\mathrm{CO}_{2}$ emissions led to a $49.7 \%$ share of renewables in the generation mix in 2050. The restriction of $\mathrm{CO}_{2}$ emissions led to a $49.7 \%$ share of renewables in the generation mix in 2050. CSP installations, which spread weakly in the baseline scenario, start with a capacity of $0.32 \mathrm{GW}$ in 2016 and reach $2.51 \mathrm{GW}$ in 2050 , this is mainly due to its cost, which becomes economic in terms of production. In addition to these characteristics, the electricity produced by thermal power plants decreases in the baseline scenario in 2050 from $61.1 \%$ to $45.2 \%$.

Based on Fig. (9), the restriction on $\mathrm{CO}_{2}$ emissions resulted in a $49.7 \%$ share of renewables in the production mix in 2050. The CSP installations, which have been spread weakly in the baseline scenario, start with a capacity of $0.32 \mathrm{GW}$ in 2016 and reach $2.51 \mathrm{GW}$ in 2050 , this is mainly explained by its cost, which becomes economical in terms of production. In addition to these characteristics, the electricity generated by thermal power plants decreases in the baseline scenario in 2050 from $61.1 \%$ to $45.2 \%$.

\subsubsection{Scenario for the Introduction of a Carbon Tax}

The carbon tax scenario examines the effect of the introduction of the carbon tax constraint on Morocco's optimal generation system developed by the OSeMOSYS model. The results show an $11.4 \%$ increase in renewable energy capacity and a $5.68 \%$ decrease in thermal capacity in 2050 with the introduction of a high tax $\left(\$ 125 /\right.$ tonne of $\left.\mathrm{CO}_{2}\right)$. Compared to the emission ceiling, the introduction of the tax favors the integration of natural gas in the electricity mix because of its low pollution level.

Compared to the baseline scenario, fossil fuel-based electricity decreased by $29.8 \%$ to 72.62 TWh in 2050 . On the other 


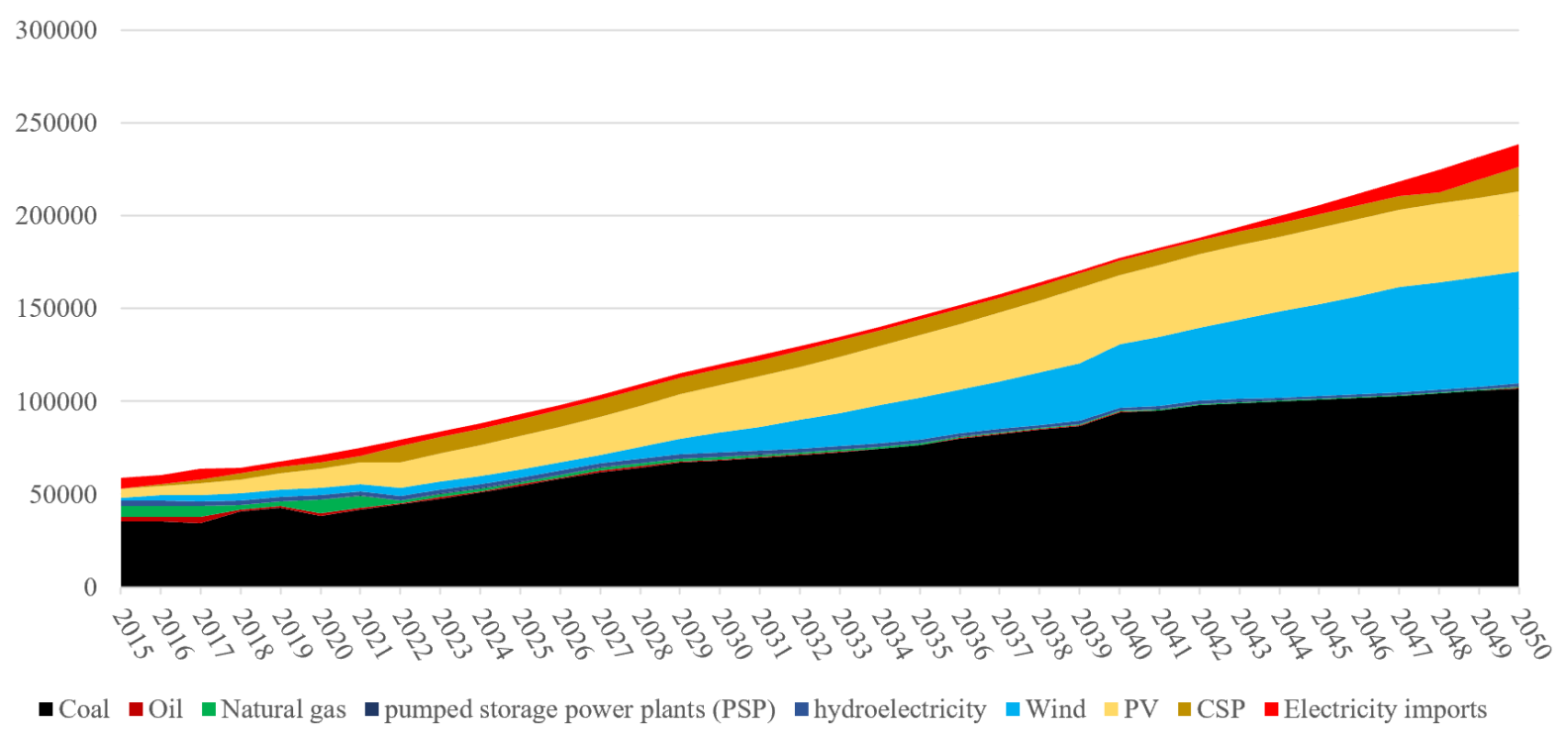

Fig. (9). Evolution of the Moroccan electricity generation mix in the $\mathrm{CO}_{2}$ emissions cap scenario during the modeling period 2015-2050 in (GWH).

Source: Realization of the authors.

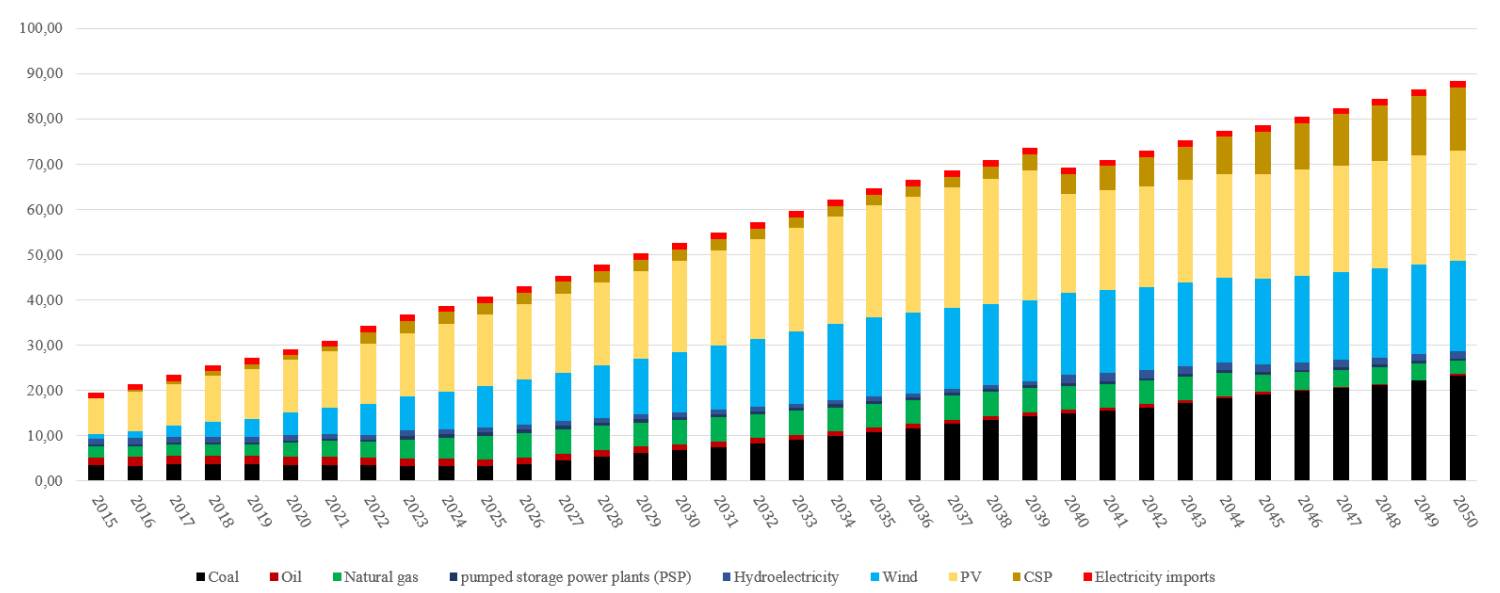

Fig. (10). Evolution of the Moroccan electricity mix in the carbon tax scenario during the modeling period 2015-2050 in (GW). Source: Realization of the authors.

hand, electricity generation from renewable energies increased by $26.3 \%$ to 156.95 TWh Fig. (11). These results indicate that a carbon tax will have a direct effect on the production cost of polluting energies and will make renewable energies more economically sustainable.

These results also show that the alternative scenarios introduced higher capacities than the reference scenario. This is due to the high penetration of renewable energy. These results agree are with those of (McPherson and Karney, 2014) and (Awopone and Zobaa, 2017), who propose that higher capacities of renewables are essential to cover the same demand as thermal plants due to lower capacity factors.

\subsection{Economic and Environmental Analysis}

These analyses aim to assess the economic and environmental impact of the scenarios proposed in this study. The objective is to identify the optimal paths in terms of costs to achieve the given objectives.

\subsubsection{Economic Analysis}

The cost-benefit analysis method was used for the economic evaluation of the different scenarios in this study. The objective is to determine the best approach by comparing the costs and benefits of the alternative scenarios. The cost of the power system is expressed as the net present value of capital costs, operating costs (fixed and variable costs), emission costs, and recovery costs over the study period discounted at $5 \%$ from the base year. The table below presents the results of the cost-benefit analysis given by the OSeMOSYS model. A positive value represents a cost, while a negative value is a benefit.

Table 2 shows that the cumulative costs of introducing a carbon tax and the $\mathrm{CO}_{2}$ emissions cap are higher than in the baseline scenario. This is mainly due to the increased expenditure related to investment in clean technologies, which are largely introduced in the electricity mix. 


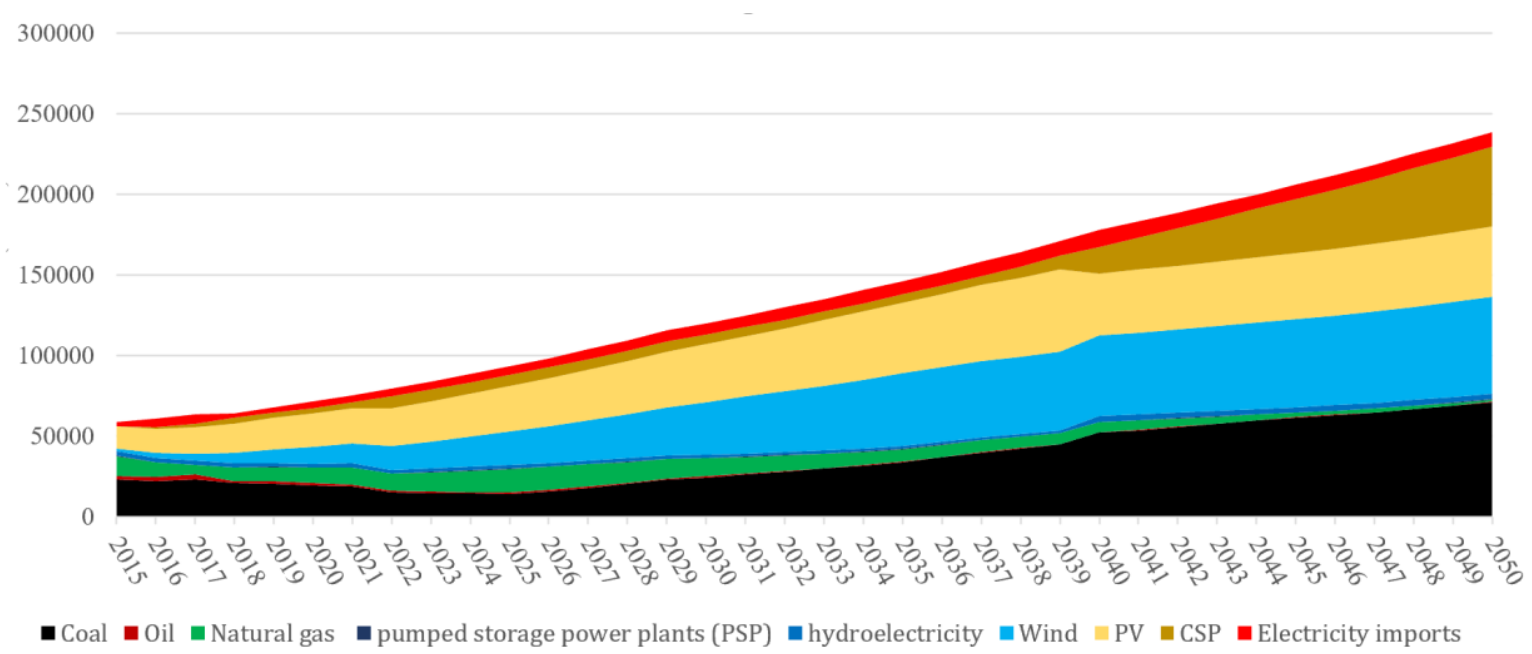

Fig. (11). Evolution of the Moroccan electricity generation mix in the carbon tax scenario during the modeling period 2015-2050 in (GWH). Source: Realization of the authors.

Table 2. Cumulative costs and benefits: $2015-2050$ compared to the reference scenario discounted at $5 \%$ to the year 2015 (in billions of dollars).

\begin{tabular}{cccc}
\hline Electrical system costs & $\begin{array}{c}\text { Reference } \\
\text { scenario }\end{array}$ & Tax Carbon & Emission cap scenario \\
\hline Capital investment & 10,30 & 14,69 & 11,71 \\
Operating costs & 2,26 & 2,00 & 2,15 \\
Emission costs & $\mathrm{O}$ & 0,52 & $\mathrm{O}$ \\
Salvage value costs & $-0,74$ & $-0,74$ & $-0,73$ \\
Total costs & 11,82 & 16,47 & 13,13 \\
\hline
\end{tabular}

Source: Realization of the authors.

Table 3. Cumulative emissions and cost of avoided $\mathrm{CO}_{2}$ emissions.

\begin{tabular}{cccc}
\hline Scenarios & $\begin{array}{c}\text { Cumulative emission } \\
\text { (Mt CO2e) }\end{array}$ & $\begin{array}{c}\text { CO2e } \\
\text { savings (\%) }\end{array}$ & $\begin{array}{c}\text { Cost of avoiding GHG } \\
\text { ((\$/tonne CO2e) }\end{array}$ \\
\hline Reference & 2527,7 & - & - \\
Emission cap & 1867,9 & $26,10 \%$ & 60,01 \\
Carbon tax & 1019,2 & $59,68 \%$ & 146,64 \\
\hline
\end{tabular}

Source: Realization of the authors.

Although these constraints allow for savings in technology recovery, these savings have been insufficient to make up for the high capital investment. Furthermore, the introduction of the tax has increased the total cost of the system relative to the reduction target. This is mainly due to the inclusion of the cost of emissions generated by conventional energies, which allows higher use of non-polluting technologies (renewable energies) in the optimal production system.

The country can therefore consider implementing one of these two carbon minimization strategies to reduce the volume of greenhouse gas emissions. These measures have proven to be very effective in addressing electricity market failures because they allow energy industries to orient their production choices in an environmentally friendly manner.

\subsubsection{Environmental Analysis}

The environmental analysis aims to assess the potential for carbon minimization. The effectiveness of the two scenarios was analyzed by calculating the cost of abatement of emissions over the entire model period. The objective is to determine the cheapest alternative to reduce one tonne of $\mathrm{CO}_{2}$.

Table 3 further indicates that a large reduction in $\mathrm{CO}_{2}$ emissions could be achieved under the carbon tax compared to the reduction target. These results show that internalizing the cost of emissions has a direct impact on the operational cost of thermal generation, which automatically leads to the deployment of renewable technologies.

The results show that both scenarios result in abatement costs. This is due to the entry of renewable energy into the generation system. Besides, the introduction of a carbon tax will result in a significant reduction in GHG emissions compared to the $\mathrm{CO}_{2}$ emissions cap scenario. The difference in results between these two scenarios comes from the different ways in which they encourage the adoption of renewable technologies. Therefore, it can be inferred that both constraints have the potential to reduce emissions, except that 
the carbon tax will have a direct and immediate effect on the deployment of renewable technologies.

\section{CONCLUSION}

The failure to take into account GHG emissions generated by the electricity sector prevents Morocco from achieving a clean energy transition. As a result, a carbon minimization strategy can be used in a "double dividend" logic favoring the emergence of non-polluting or low-pollution energies to guarantee, on the one hand, security of supply and, on the other hand, convergence towards sustainable development through the reduction of emissions.

In this framework, we used a bottom-up optimization model that allows an in-depth analysis of the impact of energy strategies on the development and deployment of technologies. Indeed, these bottom-up partial equilibrium models are constrained by two challenges: the need for specialized software that is not available to all users, and the availability of a high-quality database, two matters that remain unfavored in developing countries. To reduce the barriers to the use of this type of modeling, an open-source bottom-up energy system optimization model (OSeMOSYS) was published in 2011. This model has recently enjoyed enormous academic success, as evidenced by the large number of works that have enriched the literature on energy system modeling and thus opened up the opportunity for researchers to formalize energy policies.

In our work, the OSeMOSYS tool was used to model the electrical system in Morocco on the one hand, and to evaluate the optimal production system of the country until 2050 on the other hand. As a result, two constraints were applied to determine their repercussions on the optimal production system. The empirical study shows that the carbon minimization strategy of the optimal power system plays an important role in $\mathrm{CO}_{2}$ mitigation in Morocco. This has been verified by the integration of renewable energies in alternative scenarios. According to the results obtained, an emission reduction target and a carbon tax will significantly favor the diversification of the electricity mix, by introducing renewable energies as a less costly and sustainable alternative. This will allow a reduction in the overall production of fossil fuels in Morocco, which is characterized by an unreliable supply of raw materials and price shocks, thus improving energy reliability.

Although both constraints allow the achievement of depollution objectives, a carbon tax offers a great diversification of the electricity mix with a significant reduction in emissions. This can be explained by the internalization of the costs of emissions, which act directly on the costs of conventional technologies. The study, therefore, suggests the implementation of a carbon tax as an instrument to accelerate decarbonization and the resources from the implementation of the tax can be allocated to the financing of clean energy, to benefit from a more reliable and environmentally friendly electricity system.

However, this study has certain limitations. Firstly, the model does not allow the analysis of the interactions between the power system and other economic sectors. The prospective study has allowed us to shed more light on the optimal choices adopted by the Moroccan electricity system to cope with environmental constraints. Within the framework of enriching our study, other avenues of research can be explored to unveil the economic advantages of renewable energies. These are linked to scenarios related to fuel prices, assumptions on technology costs, and improved transmission and distribution losses.

\section{CONFLICT OF INTEREST STATEMENT}

The authors declare that they have no conflict of interest.

\section{REFERENCES}

Afif, M. (2012). Incitation à l'adoption de technologies propres (No. 2012 11). Bureau d'Economie Théorique et Appliquée, UDS, Strasbourg.

Aliyu, A.S., Ramli, A.T., Saleh, M.A., (2013). Nigeria electricity crisis: power generation capacity expansion and environmental ramifications. Energy, 61, 354-367.

Awopone, A., Zobaa, A. (2017). Analyses of optimum generation scenarios for sustainable power generation in Ghana. AIMS Energy, 5, 193 208.

Bazilian, M., Rice, A., Rotich, J., Howells, M., DeCarolis, J., Macmillian, S., Brooks, C., Bauer, F., Liebreich, M. (2012). Open-Source software and crowdsourcing for energy analysis. Energy Policy, 49, 149-153.

Bazmi, A.A., \& Zahedi, G., (2011). Sustainable energy systems: Role of optimization modeling techniques in power generation and supply-A review. Renewable and Sustainable Energy Reviews, 15(8), 3480-3500.

Becerra-López, H. R., \& Golding, P. (2008). Multi-objective optimization for capacity expansion of regional power-generation systems: A case study of far west Texas. Energy Conversion and Management, 49(6), 1433-1445.

Benhima,D. (1999). Les réformes du secteur électrique : le cas du Maroc. Liaison énergie francophonie, 44, 33-35.

Brand, B., Missaoui, R., (2014). Multi-criteria analysis of electricity generation mix scenarios in Tunisia. Renew. Sustain. Energy Rev, 39, 251-261.

Capros, P., Tasios, N., De Vita, A., Mantzos, L., \& Paroussos, L. (2012). Model-based analysis of decarbonizing the EU economy in the time horizon to 2050. Energy strategy reviews, 1(2), 76-84.

Chaudry, M., Jenkins, N., Qadrdan, M., Wu, J., (2014). Combined gas and electricity network expansion planning. Appl. Energy, 113, 11711187.

Chentouf, M. A., \& Allouch, M. A. (2018). Renewable and alternative energy deployment in Morocco and recent developments in the national electricity sector. Open Access Journal Photoenic, 2(1), 00017.

Choukri, K., Naddami, A., \& Hayani, S. (2017). Renewable energy in emergent countries: lessons from energy transition in Morocco. Energy, Sustainability and Society, 7(1), 1-11.

Dhakouani, A., Gardumi, F., Znouda, E., Bouden, C., Howells, M. (2017). A long-term optimization model of the Tunisian power system. Energy, 141, 550-562.

Groissböck, M., Pickl, M. (2016). An analysis of the power market in Saudi Arabia: Retrospective cost and environmental optimization. Applied energy, 165, 548-558.

Howells, M., Rogner, H., Strachan, N., Heaps, C., Huntington, H., Kypreos, S., ... \& Roehrl, (2011). OSe-MOSYS: the open-source energy modeling system: an introduction to its ethos, structure, and development. Energy Policy, 39(10), 5850-5870.

International Energy Agency, France, Energy Policies Beyond IEA Countries: Morocco Annual report, 2019.

Carlsson, J., Fortes, M. D. M. P., de Marco, G., Giuntoli, J., Jakubcionis, M., Jäger-Waldau, A., ... \& Weidner, E. (2014). ETRI 2014-Energy technology reference indicator projections for 2010-2050. European Commission, Joint Research Centre, Institute for Energy and Transport, Luxembourg: Publications Office of the European Union.

Lienert, M., Lochner, S. (2012). The importance of market interdependencies in modeling energy systems - the case of the European electricity generation market. Electr. Power Energy Syst, 34, 99113.16 . 
Lyseng, B., Rowe, A., Wild, P., English, J., Niet, T., \& Pitt, L. (2016). Decarbonizing the Alberta power system with carbon pricing. Energy Strategy Reviews, 10, 40-52.

McPherson, M., Karney B. (2014) Long-term scenario alternatives and their implications: LEAP model application of Panama's electricity sector. Energy Policy, 68, 146-157.

Ministère délégué auprès du Ministère de l'Energie, des Mines, de l'Eau et de L'Environnement, Secteur de l'énergie - Chiffres clés., Rapport annuel, Maroc, 2019.

Mondal, M.A.H., Kamp, L.M., \& Pachova,N.I. (2010). Drivers, barriers, and strategies for implementation of renewable energy technologies in rural areas in Bangladesh-An innovation system analysis. Energy Policy, 38(8), 4626-4634.

Mondal, M.A.H., Mathur, J., \& Denich, M. (2011). Impacts of $\mathrm{CO}_{2}$ emission constraints on technology selection and energy resources for power generation in Bangladesh. Energy Policy, 39(4), 2043-2050.

Nakata, T., Lamont, A. (2001). Analysis of the impacts of carbon taxes on energy systems in Japan. Energy Policy, 29(2), 159-166.

Office National de l'Electricité et de l'eau potable (ONEE), Maroc, Annual reports 2004 and 2019.

Shahmohammadi, M.S., Yusuff, R.M., Keyhanian, S., Shakouri, H.G., (2015). A decision support system for evaluating effects of Feed-in
Tariff mechanism: dynamic modeling of Malaysia's electricity generation mix. Appl. Energy, 146, 217-229.

Welsch, M., Deane, P., Howells, M., Gallachóir, B.Ó., Rogan, F., Bazilian, M., Rogner, H.H. (2014). Incorporating flexibility requirements into long-term energy system models - a case study on high levels of renewable electricity penetration in Ireland. Appl. Energy, 135, 600-615.

Welsch, M., Howells, M., Bazilian, M., DeCarolis, J.F., Hermann, S., Rogner, H.H. (2012). Modeling elements of smart grids - enhancing the OSeMOSYS (open-source energy modeling system) code. Energy, 46, 337-350.

Wu, J.-H., Huang, Y.-H., (2014). Electricity portfolio planning model incorporating renewable energy characteristics. Appl. Energy, 19, 278287.

Yang, C., Yeh, S., Zakerinia, S., Ramea, K., \& McCollum, D. (2015). Achieving California's $80 \%$ greenhouse gas reduction target in 2050: technology, policy, and scenario analysis using CA-TIMES energy-economic systems model. Energy Policy, 77, 118-130.

Zouiri, H., \& Elmessaoudi, H. (2018). Energies renouvelables et développement durable au Maroc. Revista de Estudios Fronterizos del Estrecho de Gibraltar, (6), 1-29.

Copyright $($ C 2021- All Rights Reserved

This is an open-access article. 